\title{
USING SIMIO FOR THE SPECIFICATION OF AN INTEGRATED AUTOMATED WEIGHING SOLUTION IN A CEMENT PLANT
}

\author{
Pavel Vik \\ Technical University of Liberec \\ Department of Manufacturing Systems \\ Studentská 2 \\ Liberec, 461 17, CZECH REPUBLIC
}

\author{
Luis Dias \\ Guilherme Pereira \\ José Oliveira \\ Universidade do Minho Centro \\ Centro ALGORITMI \\ Campus de Gualtar \\ Braga, 4710 - 057, PORTUGAL
}

\author{
Ricardo Abreu \\ Cachapuz Braga \\ Parque Industrial de Sobreposta \\ Apartado 2012 \\ Braga, 4701-952, PORTUGAL
}

\begin{abstract}
This paper focuses on the use of a discrete simulation tool (SIMIO) in the logistic system design of a cement plant. This research project specifies a proposal of using Discrete Event Simulation (DES) and innovative logistic methods for the correct specification of an integrated weighing solution in a cement plant. This specification will then help the design phase of the whole plant and will contribute for the rationalization of the use of cement plant resources. The proposed monitoring weighing system (Cachapuz SLV Cement) together with the simulation model will evaluate different scenarios as far as the logistic system is concerned and will support important decisions in the design phase of a cement plant, contributing to the best use of the best set of resources.
\end{abstract}

\section{INTRODUCTION}

\subsection{Cement Production Plant}

Cement production industry is one of the key industries in the world economy as it definitely influences many other industries where the key factor is the building and construction industry.

In this type of factory, the flow of materials could be enormous; more than 500 trucks per day with more than 50 tons of material supply a medium size cement plant and more than 250 trucks with 30 tons of cement are loaded every day. The need for a great logistic system is then crucial. 


\section{Vik, Dias, Pereira, Oliveira and Abreu}

\subsection{General Plant}

One important fact related to the cement business is the global spreading of the cement groups and the consequent need to standardize technologies and plant layouts. Based on Figure 1, nine of top ten cement group leaders in the world adopted SAP ERP in order to control and fast adjust to the new market needs.

The same is valid to the plant layouts since cement groups tend to replicate the business models making small adjustments according to local market needs.

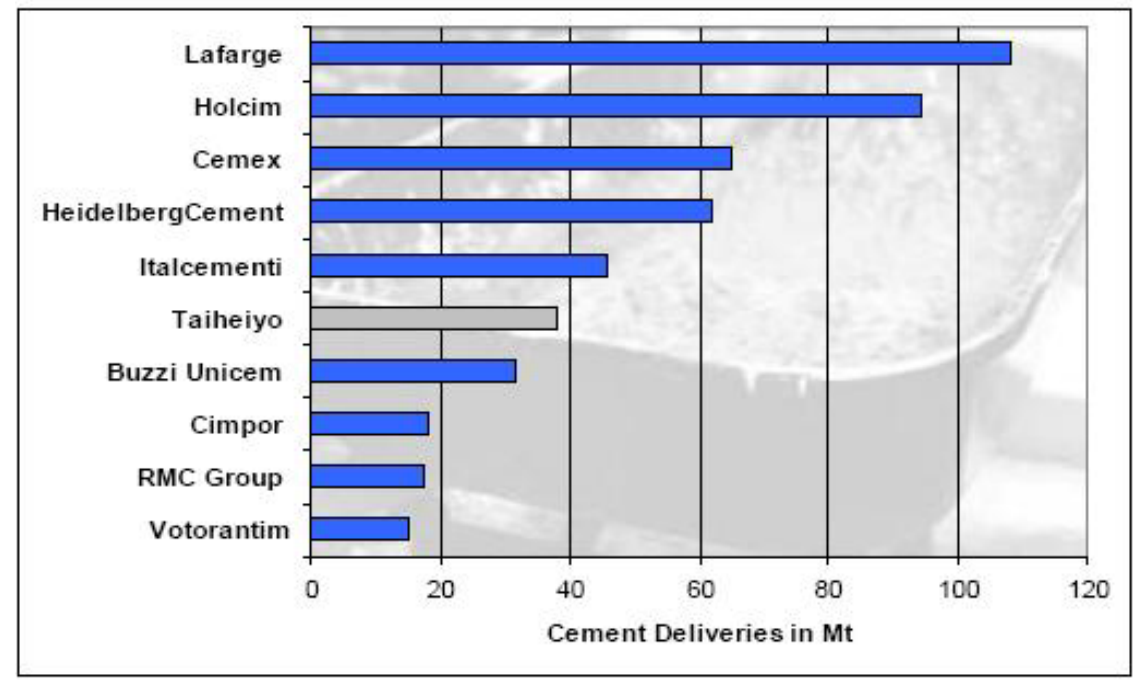

Figure 1: Implementation of SAP in a cement plant (Rasool 2008)

Figure 2 shows a typical configuration of a cement plant with the identification of the basic areas:

1. Parking area, where trucks wait for the registration of their arrival;

2. Entrance and exit gates - check zones (usually with weight bridges). The main purpose is the final confirmation of the net weight as the difference of weights when arriving and leaving the plant;

3. Loading of cement product into bulk trucks in silos, where the truck is filled through automated equipment directly from the storage area;

4. Loading of cement product stored in bags in a warehouse. This type of loading can have a low automation level (conveyor and human power) or a higher level with the use of pallets (depending on the type of commerce and market requirements). This area is usually responsible for most failures in the process, as far as the correct type of material and correct amount of material is concerned. This area is identified as critical in a cement plant;

5. Supplying and unloading raw material. It is usually convenient to treat this type of processes separately once the respective large number of trucks can cause serious flow problems inside the plant.

It is then possible to identify problematic areas and respective aims:

- Loading processes - the aim is to avoid errors in loading, making use of standard loading times;

- Avoiding plant overcrowding and traffic jams inside of the plant;

- Rationalizing the use of resources (gates, loading places or human resources) and allowing flexible reactions to specific customer requirements. 


\section{Vik, Dias, Pereira, Oliveira and Abreu}

The main issue of this project will involve the integration of the SLV Cement logistic system and a discrete-event simulation software tool (SIMIO). This approach will help find a high performance configuration and control of logistic components in cement plants. These components include weighing systems in both entrance and exit gates, registering and managing customer orders and requirements, truck flow control, etc.

Our project focuses on the identification of bottlenecks in the system, finding a set of possible solutions and choosing the best one. DES is used for this purpose (Francis, McGinnis, and White 1992).

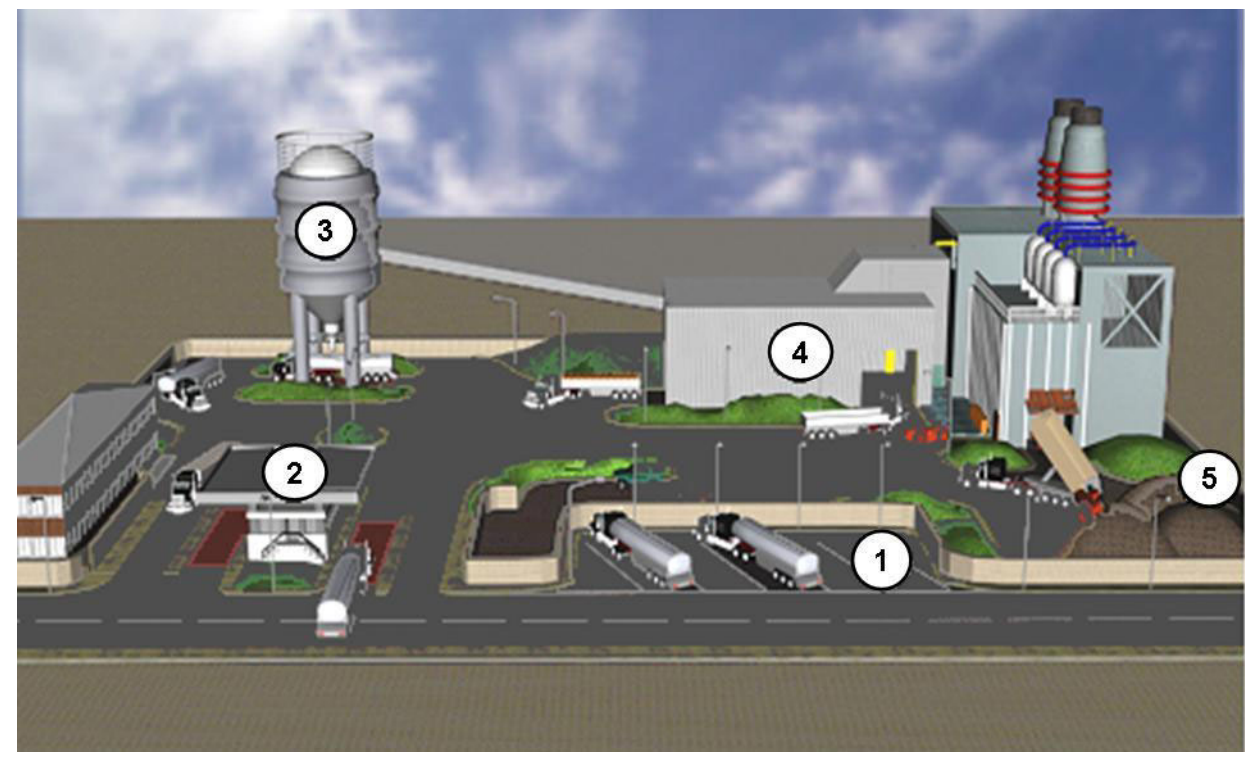

Figure 2: Configuration of a cement plant

\subsection{SLV Internal Logistic System}

SLV Cement is a complete logistic system for cement plants developed by Cachapuz. This automatic and integrated logistic system deals with all the processes since the arrival of a truck to the cement plant to the shipping of cement. At the end of the process, even the administrative tasks like issuing and printing the necessary documentation are performed automatically. Another interesting SLV feature is the complete integration with SAP business software (ERP).

This proposed fully integrated logistic system will permit to increase throughput (trucks per unit time) and reduce the number of operators needed, thus avoiding human errors.

The following picture (Figure 3), presents the main system architecture. Based on a central core, a set of different modules like reporting, automation and control, alerts (with SMS and mail sending), process logs and extensibility with external ERPs, were developed. Over these modules, the different plant areas like parking, check-in / check-out, raw material unloading zones, bag warehouses or bulk-loading, will be customized and automated. Additionally, as an answer to the global spread of the SLV system, the platform is fully prepared to remote support allowing fast diagnosis of and response to any factory needs.

\subsection{Discrete Event Simulation (DES)}

DES is the act of imitating the behavior of an operational system or process using an analog conceptual model on a computer. The arguments below will help understand why simulation would be a useful tool:

- All processes have stochastic behavior (Kulturel 2007);

- It is a complex system with many resources and non deterministic conditional routing decisions; 


\section{Vik, Dias, Pereira, Oliveira and Abreu}

- 3D graphic and animation is relevant for easy demonstration and presentation;

- Need for simulating crashes and breakdowns in real processes (e.g. printer breakdown, electric failures, human errors etc.);

- Need for analysis of time dependent patterns of demand and facilities/resources availability.

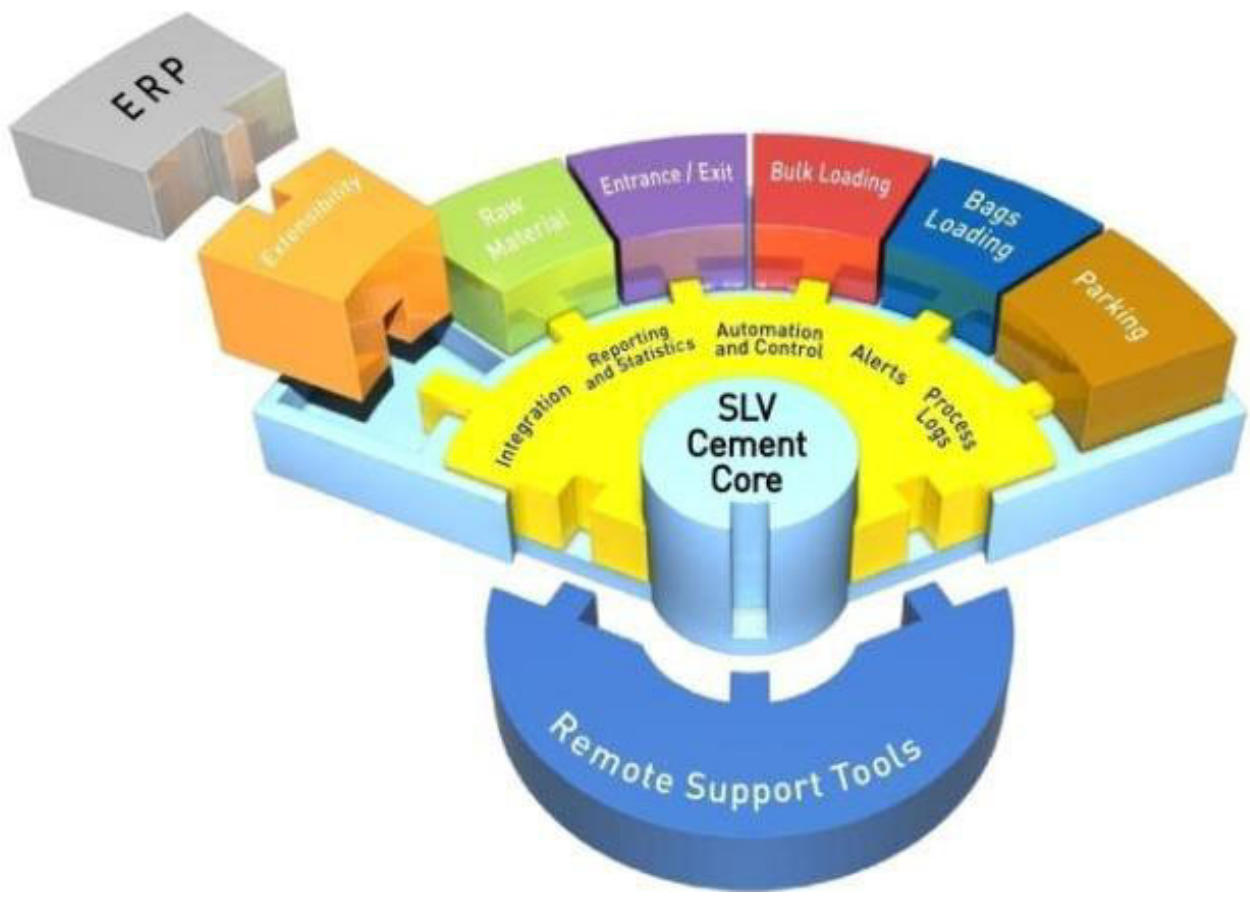

Figure 3: SLV Cement Logistic system

\subsection{SIMIO}

SIMIO is a quite new simulation tool; it was developed in 2007 and represents a new approach in simulation - object orientation. Modeling is based on describing system's objects and evolution of system behavior by interaction of these objects (Pegden 2007). SIMIO supports:

- Creating 3D animation on one step, importing 3D objects from Google 3D Warehouse (Figure 9);

- Importing data from Excel worksheets (snapshot in Figure 6);

- Writing own logic functions (e.g. priority rules) in many languages (C++, Visual Basic, etc.) (snapshot in Figure 7);

- Creating our own intelligent objects and libraries.

For this project, SIMIO simulation software was chosen in a perspective of a new challenge in this area (other simulation tools are discussed in Dias, Pereira, and Rodrigues 2007), and the issues below gained a great relevance for this project:

- Testing a new simulation tool for setting it as a part of currently used internal logistic system;

- Testing new possibilities for introducing this new simulation tool for educational purposes in our department. 


\subsection{Integration of a Simulation Tool and the Logistic System}

According to mentioned issues, it is possible to identify why implementation of DES would be relevant in the context of a cement company:

- Currently used logistic application manages the flow of trucks in the plant;

- It helps answer what-if questions, checking (testing) the impacts of system changes;

- The plant processes and control logic are in the minds of managers and changes are made based on their knowledge (experience) and not on proved scenarios.

It is possible to make use of the integration of these tools in two different contexts, see Figure 3.

- Improving and optimizing a plant system that already uses SLV logistic system (current customers);

- Supporting the implementation of SLV system for new customers.

The first approach (see schema in Figure 4, left side of the figure) can help in re-design tasks, testing different scenarios and suggesting configuration changes. The simulation model gives answers to "whatif' analysis and shows impacts and influences of tested changes in the overall performance.

Simulation can also be used for the implementation of a new logistic system in a new plant (Figure 4 , right side of the figure). In this case simulation is a great tool and the 3D animation will help visualize a non-existing system and it is therefore possible to suggest and configure a complete system before its implementation in the plant. The DES will then help the specification of the global logistic system in close connection with the integrated automated weighing system proposed.

According to the number of known projects, it is possible to say that re-design tasks are much more often than the design of completely new logistic systems (Kulturel 2007) (Vik 2009).
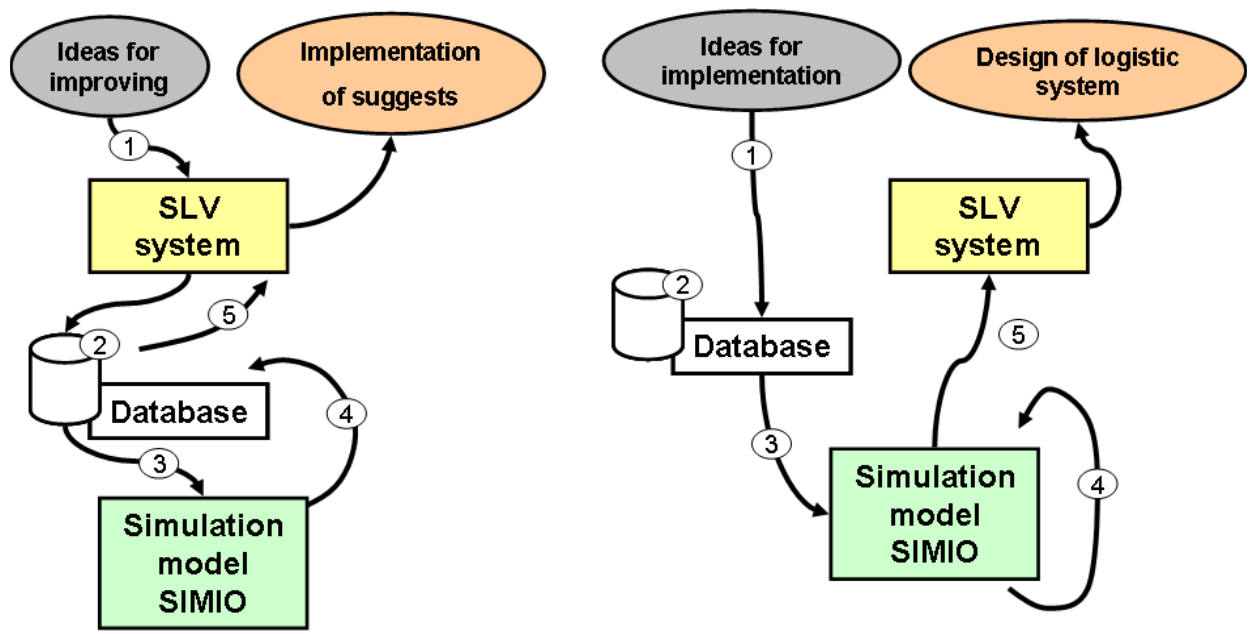

Figure 4: Schema of two different uses of integration approaches

\section{PROBLEM DESCRIPTION AND PROJECT STEPS}

As an illustrative example of the mentioned integration principles and for an easy understanding, we chose a simple model of a real cement plant and its logistic processes. This solution is based on general usage in any cement (or similar) kind of factory.

Our simulation approach included the steps proposed in Muther (1973), Taylor (2008), Zelinka (1995), and are illustrated below (according to

Figure 4). 
1) Definition of project aims

- Definition of exact project targets according to customer requirements;

- Setting of system's borders and level of detail;

- Team building and its responsibility.

2) Processing of input data

- Technical data (facilities data, product data, information about material flows, production areas, breakdowns, shifts etc.);

- Organization data (production scheduling);

- Business data (costs, orders).

3) Creation of simulation model

- Conceptual model (schematic);

- Computer model.

4) Simulation run and experiments

- Validation and model verification;

- Setting of parameters, length of simulation run;

- Running of experiments.

5) Interpretation of results and implementation

- Data analysis;

- Interpretation of results, their presentation and comparing suggested alternatives and scenarios (graphs, tables, 3D animation).

\subsection{Short description and definition of project aims}

In Figure 5, there is a schema of this system. There are several types of trucks according to the kind of loads (incoming trucks with raw material and outgoing trucks with final cement products)

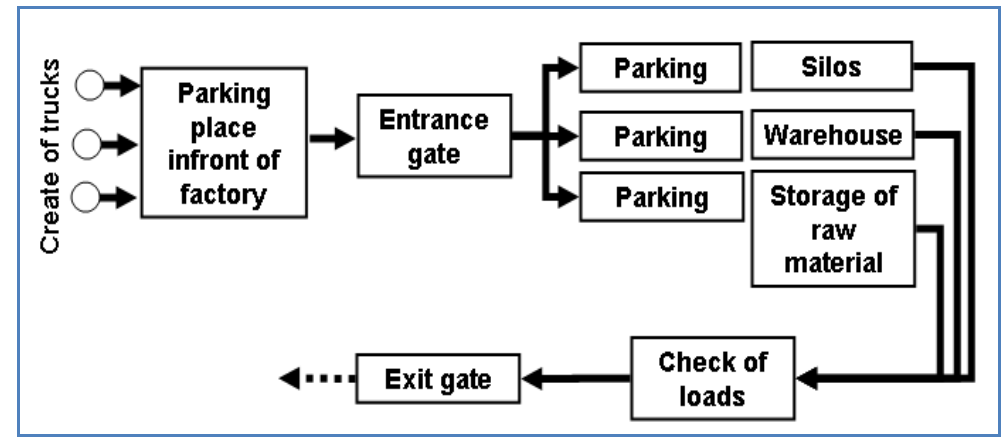

Figure 5: Schema of a simple production system

These trucks must go through the entrance gates where they are registered and weighed. After that, they are sent into correct location in the plant for loading or unloading material. Then, trucks are weighed again and after final checking, they can leave the plant through the exit gates.

Through a preliminary analysis, some predictable problems would arise. Mainly, in this type of factories, the length of queues in some specific factory facilities - entrance gates, for example, always constitutes a relevant problem, causing long waiting times for customers. Usually this problem is due to inadequate number of facilities/resources available (e.g. loading places in warehouse) or to long loading times. Also, an inadequate control of work flows would lead to:

- Wrong destinations associated to trucks, once inside the plant;

- Trucks waiting even when facilities are available; 
- Bad administrative options and absence of modern registration technologies as magnetic cards;

- Traffic jam inside plant;

- Incorrect loads;

- Breakdowns of key facilities;

- Inadequate Production scheduling.

Though, DES could be a powerful tool to improve processes and draw suggestions for modern control systems implementation (Benjaafar, Heragu, and Irani 2002).

\subsection{Processing of input data}

For a correct analysis and the creation of an adequate simulation model, it is necessary to use valid data as:

- Definition of operations (inputs and outputs, production times etc.);

- Productive facilities and their properties (capacity, transport speeds, breakdowns statistics etc);

- Layout specifications and graphical models for entities and facilities (for realistic animation 3D models of facilities can be used, that are downloadable from Google 3D Warehouse);

- Possible truck routings through production facilities and respective control logic;

- Workers and their properties (capabilities);

- Production scheduling;

- Demand patterns (rate tables of arriving trucks);

- Patterns of failures;

- Shifts management.

These data are processed for making analysis and formatted to SIMIO as it is shown in Figure 6 (rate table of trucks within a day and an example of production times).

\begin{tabular}{|c|c|c|}
\hline $\begin{array}{l}\text { Starting } \\
\text { Off set }\end{array}$ & Ending offset & $\begin{array}{l}\text { Rate (events } \\
\text { per hour) }\end{array}$ \\
\hline Day 1, 00:00:00 & Day 1, 01:00:00 & 10 \\
\hline DaY 1, 01:00:00 & Day 1, 02:00:00 & 12 \\
\hline Day 1, 02:00:00 & Day 1, 03:00:00 & 23 \\
\hline Day 1, 03:00:00 & Day 1, 04:00:00 & 7 \\
\hline Day 1, 04:00:00 & Day 1, 05:00:00 & 10 \\
\hline Day 1, 05:00:00 & Day 1, 06:00:00 & 5 \\
\hline Day 1, 06:00:00 & Day 1, 07:00:00 & 5 \\
\hline Day 1, 07:00:00 & Day 1, 08:00:00 & 14 \\
\hline Day 1, 08:00:00 & Day 1, 09:00:00 & 23 \\
\hline Day 1, 09:00:00 & Day 1, 10:00:00 & 49 \\
\hline Day 1, 10:00:00 & Day 1, 11:00:00 & 58 \\
\hline Day 1, 11:00:00 & Day 1, 12:00:00 & 55 \\
\hline Day 1, 12:00:00 & Day 1, 13:00:00 & 50 \\
\hline Day 1, 13:00:00 & Day 1, 14:00:00 & 57 \\
\hline Day 1, 14:00:00 & Day 1, 15:00:00 & 42 \\
\hline Day 1, 15:00:00 & Day 1, 16:00:00 & 2 \\
\hline Day 1, 16:00:00 & Day 1, 17:00:00 & 31 \\
\hline Day 1, 17:00:00 & Day 1, 18:00:00 & 55 \\
\hline Day 1, 18:00:00 & Day 1, 19:00:00 & 54 \\
\hline Day 1, 19:00:00 & Day 1, 20:00:00 & 55 \\
\hline Day 1, 20:00:00 & Day 1, 21:00:00 & 48 \\
\hline
\end{tabular}

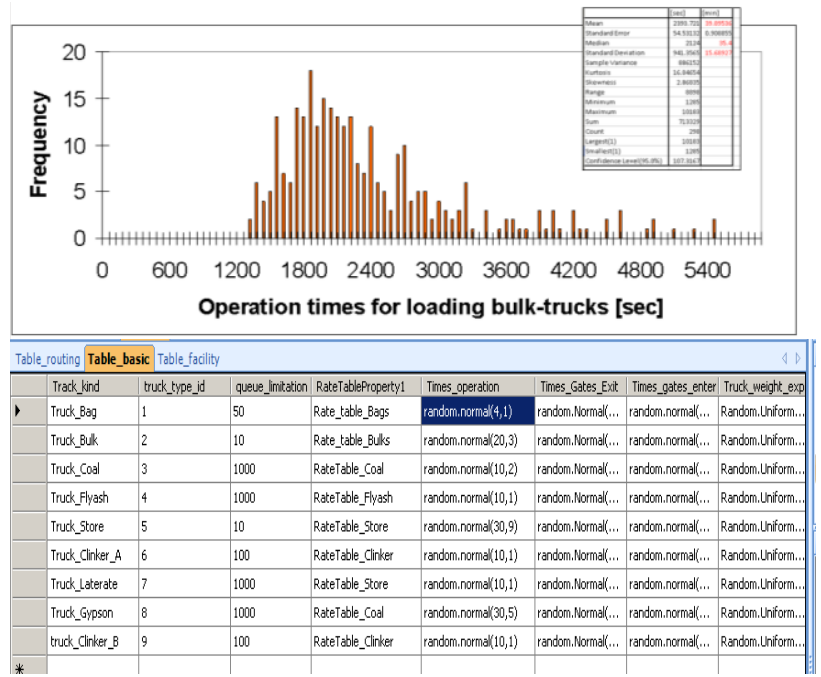

Figure 6: Input data (arrival rate and distribution function) and its representation in SIMIO

\subsection{Creation of the simulation model}

For the creation of a simulation model, standard elements like source, process and sink were used, connected by a set of paths. 
Some main processes were identified:

- Loading request registration;

- Waiting for calling to entrance;

- Entrance gate and respective weighing (both empty and loaded trucks);

- Loading/unloading (silos, warehouse, storage of raw material and storage of lime stone);

- Load checking;

- Exiting gate (weighing).

Some random variables were studied:

- Patterns of time between arrivals at different periods of the day and different days;

- Operation times;

- Failures of facilities, errors in loading actions.

For describing a realistic behavior of the trucks in the plant, some special functions were created. For avoiding traffic jams inside the plant, a limitation function is used - only a limited number of trucks could be inside the plant at the same time (remaining trucks should wait for a call outside the plant). In real plants (with SLV system), the waiting trucks are then called, using either an outside panel information board or even sending an SMS to the driver's mobile phone.

For finding the next destination (in the model represented as element "node") wherever the roads fork, another function is used. Process diagram of this function is shown in Figure 7. A typical use of this function would be for performing the task of finding the correct entrance gate. Each truck has a set of attributes like identification number and weight. According to these data, function finds optimal destination for a truck by searching in the "Table_routing" that contains all data about possible routes for each kind of truck. Searching is based on this information:

- Kind of truck (raw material trucks use a special gate);

- Weight limitation of gate (e.g. 60 tons);

- Current queues in front of each suitable gate;

- Current state of facility (if there is some failure, another gate should be chosen).

If there is no free gate, the truck will wait in the queue until another truck leaves some of the gates.

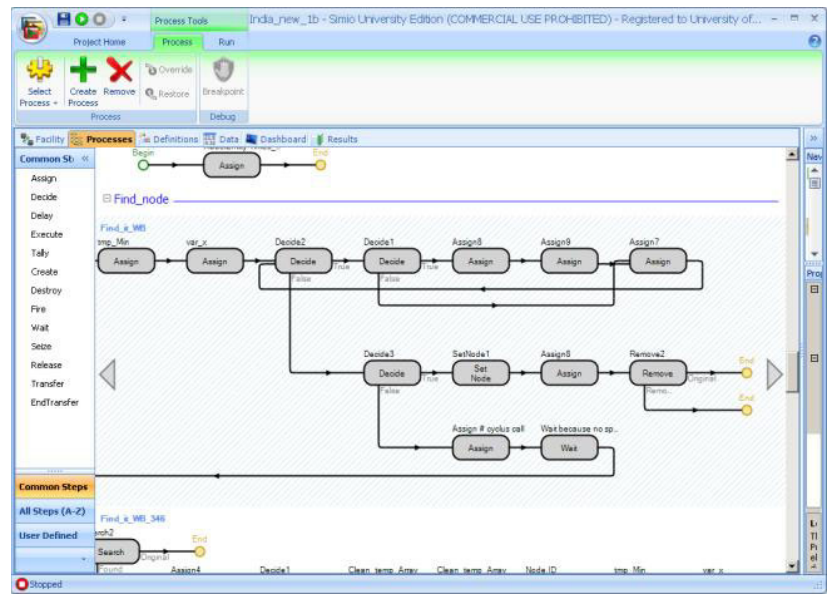

\begin{tabular}{|c|c|c|c|c|c|c|c|c|}
\hline \multicolumn{6}{|c|}{ Table_routing Table__bsect Table_faclity } & \multirow{2}{*}{\multicolumn{2}{|c|}{ Node_neme_decite! ID_mods_deride }} & \multirow{3}{*}{$\frac{41}{\text { inpul_but }}$} \\
\hline ID_tuds & gate_Inititoton & Resour & If Input_buffe__apa & Eventiexit & ID_notes & & & \\
\hline 1 & 30 & WE-3 3 & WE__i.Inputtuff'... & Event_leave_fa.... & Inputigwe_3.ID & Deside_1 & Desidg__IID & \\
\hline 1 & 60 & WE_ 4 & WB_tInputeuff... & Event_leave_fa.... & 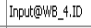 & Deside__ & Desida_t.ID & 3 \\
\hline 1 & 0 & WE 6 & WE G, inputeuff... & Event_leave_fa... & Inou:@WWE_6II & Deside_1 & Desids_1.1D & 3 \\
\hline 2 & 30 & WB_ 3 & WB_3.Inputtuff',... & Event_leave_fa.... & 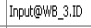 & Deside_1 & Desidg_LID & 3 \\
\hline 2 & 6 & WE_4 & WE__inputeuff... & Evert_logese_áa... & Inout@i)WE_4II & Deside_1 & Desids_t.ID & 3 \\
\hline 2 & 0 & WE_ 6 & WB_Gi,Inputtuff'... & Event_leave_fa.... & ImputiQWE_G. & Deside_1 & Desidg__IID & 3 \\
\hline 3 & 90 & WB_? & WB_.Jnputtuff... & Event_leave_fa... & Imputiwiwe 7.ID & Desid___ & Desid__I.ID & 3 \\
\hline 4 & 3 & WE_3 & WE__inputeuff,... & Event_lesve_fa.... & 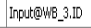 & Deside_1 & Desids_.1.ID & 3 \\
\hline 4 & 60 & WB_4 & WB_4.Inputteuff... & Event_leave_fa.... & 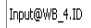 & Desid__1 & Desid__IID & 3 \\
\hline
\end{tabular}

Figure 7: Logic diagram and Routing table

Fails

One of the very important issues is the influence of fails, especially errors in loads. These errors can be caused by loading wrong material or (more often) by loading the wrong quantity. Trucks with loading er- 


\section{Vik, Dias, Pereira, Oliveira and Abreu}

rors are rejected in the dispatch area - see Figure 8 (1), and sent back for re-checking their loadings (2). Afterwards these trucks can finally leave the plant (3).

In some cases, these errors could be critical as far as the flow of trucks in the plant is concerned moreover, it implies re-use of resources to overcome the loading error.

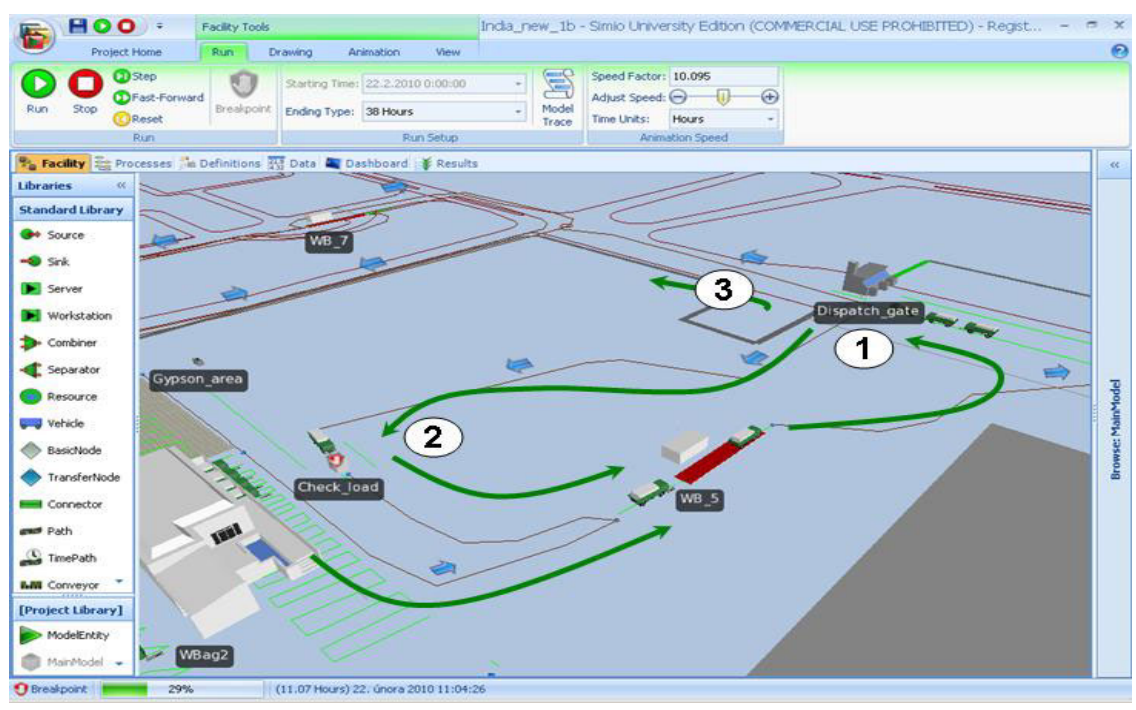

Figure 8: Rejection procedure for loaded trucks

\section{Graphic}

SIMIO supports 3D graphics and animation. It is possible to import plant layouts in ' $\mathrm{dxf}$ ' format and to use Google 3D Warehouse library for inserting 3D object models, creating realistic 3D plants. In Figure 9, there are some screenshot examples for this project.

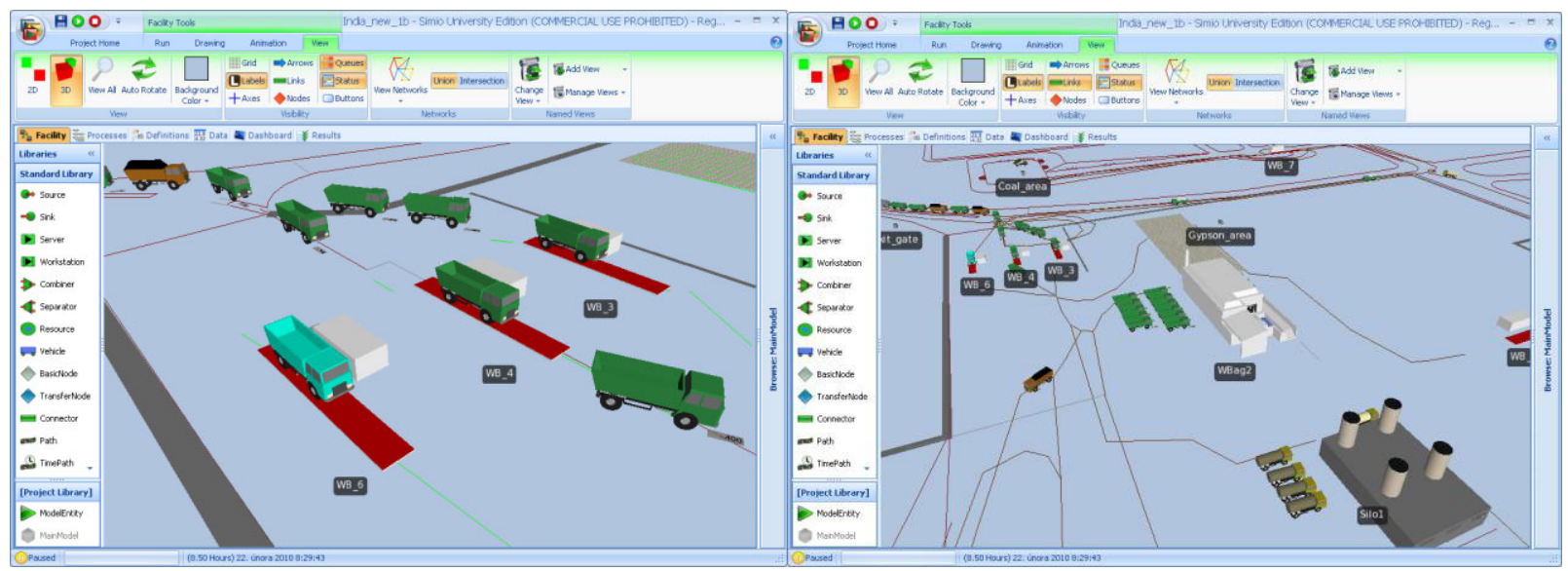

Figure 9: SIMIO model with 3D animation

\subsection{Simulation run and experiments}

One of the project aims is to find out adequate sets of parameters for system configuration:

- Number of input gates;

- Number of loading positions in the warehouse;

- Number of output gates. 
SIMIO permits to define a table of different scenarios and run several experiments (Figure 10).

\begin{tabular}{|l|l|l|l|l|l|l|}
\hline $\begin{array}{l}\text { Scenario } \\
\text { Name }\end{array}$ & Status & $\begin{array}{l}\text { Replications } \\
\text { Required }\end{array}$ & $\begin{array}{l}\text { Replications } \\
\text { Completed }\end{array}$ & number_Main_gate & number_Warehous & Number_Exit_Main. \\
\hline Scenario1 & Idle & 5 & 5 & 1 & 9 & 1 \\
\hline Scenario2 & Idle & 5 & 5 & 2 & 9 & 1 \\
\hline Scenario3 & Idle & 5 & 5 & 1 & 9 & 2 \\
\hline Scenario4 & Idle & 5 & 5 & 2 & 9 & 2 \\
\hline Scenario5 & Idle & 5 & 5 & 1 & 10 & 1 \\
\hline Scenario6 & Idle & 5 & 5 & 2 & 10 & 2 \\
\hline Scenario7 & Idle & 5 & 5 & 1 & 15 & 1 \\
\hline Scenario8 & Completed & 5 & 5 & 2 & 15 & 2 \\
\hline
\end{tabular}

Figure 10: Parameters for experimentation

Then a comprehensive report is generated. In this short prototype described, the most important performance indicators are:

- Throughput of trucks (number of trucks that enter and leave the plant per unit time);

- Facilities utilization;

- Waiting times of trucks for operation.

Results for these experiments are shown in the table in Figure 11. Each row represents the results of one experiment according to parameters shown in Figure 10.

\begin{tabular}{|c|c|c|c|c|c|c|}
\hline \multicolumn{7}{|c|}{ Main _yate - Processing Time - Percent } \\
\hline Scenario & Data Source & Category & Average & Half Width & Minimum & Maximum \\
\hline Scenariol & [Resource] & ResourceState & 29.75536 & 0.43101 & 29.18406 & 30.12347 \\
\hline Scenario2 & [Resource] & Resourcestate & 27.54864 & 0.3666 & 27.29362 & 28.0276 \\
\hline Scenario3 & [Resource] & ResourceState & 29.79054 & 1.06835 & 29.13903 & 31.21303 \\
\hline Scenario4 & [Resource] & Resourcestate & 27.49827 & 0.59905 & 26.83926 & 28.02074 \\
\hline Scenario5 & [Resource] & ResourceState & 30.51787 & 0.65836 & 29.79014 & 31.00903 \\
\hline Scenario6 & [Resource] & ResourceState & 27.69663 & 0.32508 & 27.36852 & 27.98234 \\
\hline Scenario7 & [Resource] & ResourceState & 34.42859 & 0.74333 & 33.52589 & 34.98037 \\
\hline Scenario8 & [Resource] & ResourceState & 31.20565 & 0.31892 & 30.87649 & 31.47235 \\
\hline Scenario & Data Source & Category & Average & Half Wilth & Minimum & Maximum \\
\hline Scenario1 & InputBuffer & Throughput & 2997.4 & 48.32633 & 2929 & 3020 \\
\hline Scenario2 & InputBuffer & Throughpout & 3019.4 & 35.79426 & 2997 & 3068 \\
\hline Scenario3 & InputEutfer & Throughput & 2994 & 100.69268 & 2923 & 3126 \\
\hline Scenario4 & Inputbuffer & Throughnout & 3013.6 & 72.58377 & 2943 & 3074 \\
\hline Scenario5 & Inputeutfer & Throughput & 3066 & 66.67603 & 2976 & 3105 \\
\hline Scenario6 & InputEuffer & Throughput & 3042 & 45.87545 & 3018 & 3107 \\
\hline Scenario7 & InputEutfer & Throughput & 3462.4 & 70.30244 & 3389 & 3529 \\
\hline Scenario8 & Inputeuffer & Throughiput & 3486.4 & 53.61778 & 3412 & 3524 \\
\hline
\end{tabular}

Figure 11: Results for experiments - resource utilization and throughput analysis 


\section{Vik, Dias, Pereira, Oliveira and Abreu}

\subsection{Interpretation of results and implementation}

Analyzing scenarios defined in Figure 10 and results shown in Figure 11, it is possible to conclude that the bottleneck of the current system is the number of loading places in the warehouse. Apparently, the number of gates used is adequate and it does not influence the global system throughput. It was previously thought that, due to the high number of trucks waiting in the entrance gate, the number of gates would be critical to the overall system performance. Instead, it is now clear that the main problem is concerned with the number of loading places in the warehouse - in fact this number of loading places does affect system performance.

Figure 12 shows graphically the number of trucks inside the plant during a whole week. Each plot line represents a different kind of trucks, in four different colors for: bulk, bags, raw material and lime stone. These data were obtained by exporting appropriate arrays from SIMIO and confirm previous set of conclusions.

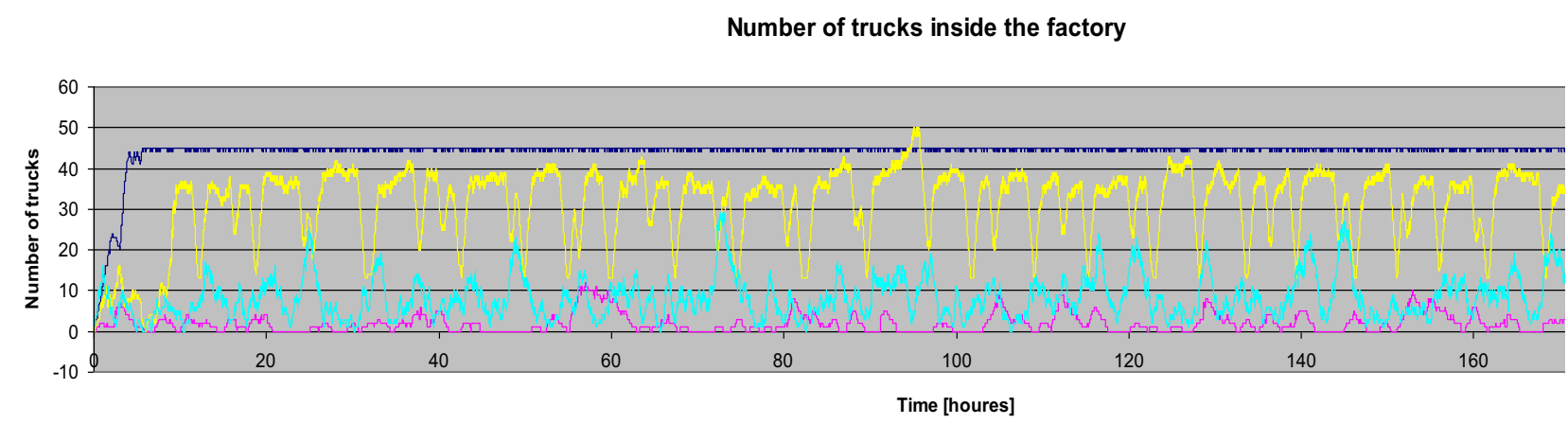

Figure 12: Number of trucks inside the factory

For trucks behavior analysis, a special array was created in order to record important moments of each truck in the system (for example arrival time for each truck, registering time, calling time, operation times, dispatching time etc.)

Results of this analysis include:

- Total time in plant;

- Waiting time in queues;

- Loading times.

Examples of these results are shown in Figure 13.

\section{RESULTS AND CONCLUSIONS}

The usage of an internal logistic system and DES for the design of this type of factory seems to be a good approach. It is possible to virtually implement a logistic control system to an existing factory and analyze corresponding impact without any type of physical intervention in the real factory - it is also possible to completely design a completely new factory.

This simulation model could also be used to:

- Testing impacts of fails, breakdowns or crashes and predicting ways of overcoming these situations;

- Creating 3D realistic detailed animation for presentation;

- Avoiding bad design decisions through previous tests with the simulation model;

- Testing system stability; 
- Evaluating stochastic influences into the design of the system;

- Achieving a global system configuration.

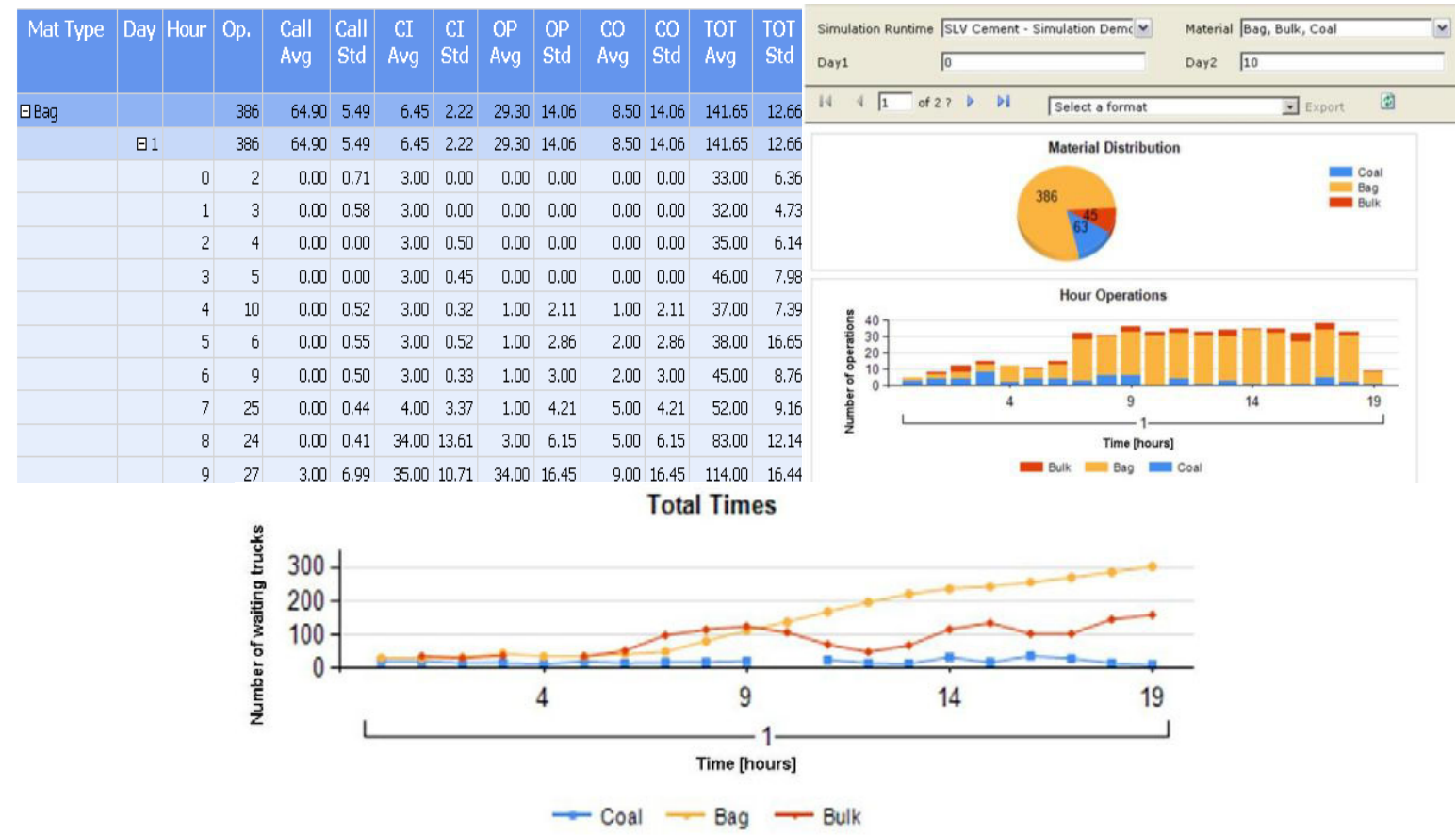

Figure 13 - Analysis of overall truck behavior

With our integrated approach, it is possible to achieve a global system configuration and find the best solution for each set of resources (e.g. facilities, space, human resources) as well as for reducing customer (trucks) waiting times. These first results do seem to be a good motivation for next steps in the use of simulation and SIMIO.

Next steps for this project would then include the definition of the entire detailed model and respective full implementation of the logistic system. Also full realistic 3D animation would be created.

\section{ACKNOWLEDGMENTS}

This project is part of a research cooperation between University of Minho (School of Engineering, Production and Systems Department) and Cachapuz. Cachapuz is a member of one of the biggest European weighing groups (the Bilanciai Group) and have a strong positioning in automation and integration of logistic operations on Cement plants.

\section{REFERENCES}

Aleisa, E., and L. Lin. 2005. For effective facilities planning: layout optimization then simulation, or vice versa? In Proceedings of the 2005 Winter Simulation Conference, eds. M. E. Kuhl, N. M. Steiger, F. B. Armstrong, and J. A. Joines, 1381-1385. Piscataway, New Jersey: Institute of Electrical and Electronics Engineers, Inc.

Benjaafar, S., S.S. Heragu, and S. Irani. 2002. Next generation Factory layouts: Research challenges and recent progress, Interface.

Dias, L.,G. Pereira, and G. Rodrigues. 2007. A Shortlist of the Most Popular Discrete Simulation Tools. Simulation News Europe, 17(1):33-36. ISSN 0929-2268. 
Francis, R.L., L.F. McGinnis, and J.A. White. 1992. Facility Layout and Location: An Analytical Approach, 2nd edition, Prentice-Hall, Englewood Clifs, NJ, USA.

Kulturel, S. 2007. Approaches to uncertainties in facility layout problems: Perspectives at the beginning of the 21th Century, In Springer Science and Business Media, Springer Netherlands, ISSN 0956-5515

Muther R. 1973. Systematické projektování (SLP), SNTL Praha.

Pegden, D. 2007. SIMIO: A new simulation system based on intelligent objects, In Proceedings of the 2008 Winter Simulation Conference, eds. S. J. Mason, R. R. Hill, L. Mönch, O. Rose, T. Jefferson, J. W. Fowler, 2293-2300. Piscataway, New Jersey: Institute of Electrical and Electronics Engineers, Inc.

Rasool, A. 2008. SAP Mill Industry - Overview, Vision and Strategy. Available via: <http://www.sap.com/westbalkans/about/news/events/Worldtour08/pdf/P1 /Ahmed Rasool Mill Products.pdf> [accessed April 14, 2010]

Taylor G. 2008. Introduction to logistics engineering, New York, Taylor \& Francis Group,

Vik, P., L. Dias, and G. Pereira. 2009. Software Tools Integration for the Design of Manufacturing Systems. In Proceedings of the Industrial Simulation Conference 2009, June 1-3, Loughborough, United Kingdom, ISBN 978-90-77381-4-89.

Zelinka, A., and M. Král. 1995. Projektování výrobních systémů, Praha: ČVUT, 1995, ISBN 80-01013302-2.

\section{AUTHOR BIOGRAPHIES}

PAVEL VIK was born in 1982 in Mladá Boleslav, Czech Republic. He studied at the Technical University of Liberec where he obtained his MSc degree in Manufacturing Systems, in 2005. He is making doctoral studies in Manufacturing Systems and Processes and he is currently at the University of Minho. His main research interest is integration of computer simulation and CAD system in area of production systems design. His email address is <vikpaveleseznam.cz>.

LUÍS M S DIAS was born in 1970 in Vila Nova de Foz Côa, Portugal. He graduated in Computer Science and Systems Engineering at the University of Minho, Portugal. He holds an MSc degree in Informatics Engineering and a $\mathrm{PhD}$ degree in Production and Systems Engineering from the University of Minho, Portugal. His main research interests are Simulation, Operational Research and Systems Visual Modeling. His email address is $<1$ sdedps. uminho.pt $>$.

GUILHERME A B PEREIRA was born in 1961 in Porto, Portugal. He graduated in Industrial Engineering and Management at the University of Minho, Portugal. He holds an MSc degree in Operational Research and a PhD degree in Manufacturing and Mechanical Engineering from the University of Birmingham, UK. His main research interests are Operational Research and Simulation. His email address is <gui@dps.uminho.pt>.

JOSÉ A OLIVEIRA was born in 1966 in Matosinhos, Portugal. He studied Mechanical Engineering at the University of Porto, Portugal. He graduated with a Ph.D. in Production and Systems Engineering at University of Minho, Portugal. His main research interests are Optimization with Heuristic Methods in Systems. His email address is <zan@dps. uminho.pt>.

RICARDO ABREU studied Systems Information at the University of Minho, Portugal. He holds a Master Degree in Business Intelligence and Data Mining. He worked in many companies focused on cement production. He works now in Cachapuz Bilanciai Group in Braga (Portugal) as senior consultant of SLV Cement solutions. His email address is <ricardo. abreu@cachapuz.com>. 